\title{
El análisis molecular de la secuencia del genoma completo de aislados clínicos de Vibrio cholerae en México en 2013 revela la presencia de la cepa causante de la epidemia de Haití en 2010
}

\author{
José Alberto Díaz-Quiñonez
}

Instituto de Diagnóstico y Referencia Epidemiológicos Dr. Manuel Martínez Báez; Facultad de Medicina, Universidad Nacional Autónoma de México, Ciudad de México, México

\begin{abstract}
Resumen
La primera semana de septiembre de 2013, el Sistema Nacional de Vigilancia Epidemiológica identificó dos casos de cólera en Ciudad de México. Los cultivos de ambas muestras se confirmaron como Vibrio cholerae serogrupo 01, serotipo Ogawa, biotipo El Tor. Los análisis iniciales por electroforesis por campos pulsados y por reacción en cadena de la polimerasa indicaron que ambas cepas eran similares, pero diferentes de las previamente reportadas en México. La semana siguiente se identificaron cuatro casos más en una comunidad del Estado de Hidalgo, ubicada a 121 kilómetros al noreste de Ciudad de México. Posteriormente se inició un brote de cólera en la región de La Huasteca. Los análisis genómicos de cuatro cepas obtenidas en este estudio confirmaron la presencia de las islas de patogenicidad VPI -1 y VPI-2, VSP-1 y VSP-2, y del elemento integrador SXT. La estructura genómica de los cuatro aislamientos fue similar a la de V. cholerae cepa 2010 EL-1786, identificada durante la epidemia en Haití en 2010. Este estudio pone de manifiesto que la epidemiología molecular es una herramienta muy poderosa para vigilar, prevenir y controlar enfermedades de importancia en salud pública en México.
\end{abstract}

PALABRAS CLAVE: Cólera. Vibrio cholerae. Filogenómica. Control de enfermedades. PFGE.

\begin{abstract}
The first week of September 2013, the National Epidemiological Surveillance System identified two cases of cholera in Mexico City. The cultures of both samples were confirmed as Vibrio cholerae serogroup O1, serotype Ogawa, biotype EI Tor. Initial analyses by pulsed-field gel electrophoresis and by polymerase chain reaction-amplification of the virulence genes, suggested that both strains were similar, but different from those previously reported in Mexico. The following week, four more cases were identified in a community in the state of Hidalgo, located $121 \mathrm{~km}$ northeast of Mexico City. Thereafter a cholera outbreak started in the region of La Huasteca. Genomic analyses of the strains obtained in this study confirmed the presence of pathogenicity islands VPI-1 and VPI-2, VSP-1 and VSP-2, and of the integrative element SXT. The genomic structure of the 4 isolates was similar to that of V. cholerae strain 2010 EL-1786, identified during the epidemic in Haiti in 2010. This study shows that molecular epidemiology is a very powerful tool to monitor, prevent and control diseases of public health importance in Mexico.
\end{abstract}

KEY WORDS: Cholera. Vibrio cholerae. Filogenomics. Diseases control. Pulsed-field gel electrophoresis.

\footnotetext{
Correspondencia:

José Alberto Díaz-Quiñonez

Francisco de P. Miranda 177

Lomas de Plateros

C.P. 01480 , Ciudad de México, México

E-mail: alberto.diaz@salud.gob.mx
}

Fecha de recepción: 07-08-2017

Fecha de aceptación: 07-09-2017

DOI://dx.doi.org/10.24875/GMM.17000010
Gac Med Mex. 2017;153;Sup 2:S91-S101

Contents available at PubMed

www.anmm.org.mx 


\section{Introducción}

El cólera es una enfermedad intestinal aguda causada por la bacteria gramnegativa Vibrio cholerae. Se caracteriza por diarrea grave y deshidratación que puede conducir a la muerte en 48 horas si no se trata adecuadamente 1 . El cólera es endémico en más de 50 países y se estima que cada año se producen entre 3 y 5 millones de casos, con aproximadamente 120,000 muertes $^{2}$.

La magnitud de una epidemia causada por $V$. cholerae se ha demostrado recientemente en Haití, donde se reportaron más de 700,000 casos con 8,700 muertes desde el comienzo de la epidemia en octubre de 2010. Se estima que, en las zonas más remotas, hasta el $5 \%$ de la población podría haber muerto en los primeros meses de la epidemia ${ }^{3}$.

$V$. cholerae se clasifica en más de 200 serogrupos basados en el antígeno $O$ presente en los polisacáridos de la pared celular; sin embargo, hasta ahora solo los serogrupos 01 y 0139 causan brotes de cólera. $V$. cholerae 01 se clasifica en dos biotipos: clásico y EI Tor (así llamado porque fue aislado por primera vez en El Tor, Egipto, en 1905)1. Existen principalmente dos serotipos: Ogawa e Inaba. La complejidad de la identificación rápida del agente causal del cólera se ha vuelto más difícil por los eventos de transferencia lateral de genes, como sucedió en 1992 en el sudeste de Asia, donde el agente causal de la epidemia fue identificado por primera vez como $V$. cholerae 0139 , una cepa derivada de $V$. cholerae $\mathrm{O} 1 \mathrm{El}$ Tor que sufrió un reemplazo de una isla de patogenicidad por transferencia lateral de genes, resultando en la sustitución de 01 por el antígeno 0139, pero en todo lo demás idéntico a V. cholerae $01 \mathrm{El} \mathrm{Tor}{ }^{2}$. Cabe destacar que, de las siete pandemias reportadas, las primeras seis fueron causadas por $V$. cholerae 01 clásico y la séptima por $V$. cholerae $01 \mathrm{El}$ Tor. La identificación de la cepa de $V$. cholerae que causa un brote se complica aún más por la presencia de secuencias de ADN que codifican resistencias a antibióticos. Tal es el caso del elemento SXT que confiere resistencia a la estreptomicina y al cotrimoxazol. Este elemento ha sido identificado en casi todas las cepas de V. cholerae El Tor en los últimos 10 años $^{1}$. Estudios recientes han informado de que el elemento $S X T$ ha sido modificado y ha adquirido resistencia a diferentes antibióticos, como la tetraciclina, la eritromicina y el ciprofloxacino, lo que se ha descrito en las cepas $V$. cholerae 01 en el sudeste asiático ${ }^{4}$. El principal determinante de la virulencia es la toxina del cólera codificada por los genes $c t x A B$ en el bacteriófago $\phi C T X$ que se encuentra en el genoma de $V$. cholerae toxigénico. Esta toxina, junto con otros factores codificados en conglomerados llamados islas de patogenicidad, es la causante de los graves efectos de la infección por $V$. cholerae ${ }^{5}$.

En México, entre 1991 y 2001 (durante la séptima pandemia) se confirmaron 45,062 casos de cólera que afectaron al $97 \%$ del país, con una tasa de mortalidad del $1.1 \%$. Desde entonces se han producido casos esporádicos de infección por $V$. cholerae serogrupo 01. Solo hubo un caso en 2010, uno en 2011 y dos en 2012, todos en el estado de Sinaloa. Los dos primeros fueron causados por $V$. cholerae 01 serotipo Inaba y los otros dos por $V$. cholerae 01 serotipo Ogawa. Al caracterizar estas cepas se encontró que eran idénticas a las cepas previamente identificadas en México en el periodo 1991-20016.

En esta comunicación se presenta el estudio de 175 casos de cólera reportados en la región de La Huasteca (parte centro-oriental de México). Los análisis genómicos moleculares demostraron que, en todos los casos, el agente infeccioso fue una cepa de $V$. cholerae toxigénica, serogrupo 01 , biotipo $\mathrm{El}$ Tor, serotipo Ogawa, diferente a los previamente caracterizados de 1991 a 2001 en México, similares a los que circulaban en el Caribe, pero claramente diferentes, como lo sugieren los resultados de filogenómica. Por primera vez se utilizó una estrategia que involucró métodos bioquímicos y genómicos moleculares para identificar de manera confiable, en un corto tiempo, el agente causal de un posible caso de cólera, que en este brote resultó ser una cepa emergente en México. Este informe demuestra que la epidemiología molecular es una herramienta esencial que proporciona información valiosa para establecer acciones que aceleren la prevención y el control de enfermedades para evitar la propagación del agente. El trabajo presentado es trascendente si consideramos que la última pandemia en México comenzó en 1991 y estuvo bajo control hasta 2001.

\section{Métodos}

\section{Obtención de muestras; medios y condiciones de cultivo}

Se obtuvieron muestras de pacientes con sospecha de cólera mediante un hisopo rectal o fecal. Se siguieron estrictamente los protocolos descritos en el 
Manual de procedimientos estandarizados para la vigilancia epidemiológica de cólera (Dirección General de Epidemiología [DGE], de la Secretaria de Salud de México). Brevemente, las muestras de materia fecal fresca se recolectaron con hisopo de algodón y se introdujeron en un tubo con medio de transporte de Cary Blair. El hisopo fue colocado en un tubo de agua peptonada alcalina (APA; peptona $1 \%, \mathrm{NaCl} 1 \%$, pH 8.5, con $\mathrm{NaOH} 3 \mathrm{M}$ ) y se incubó a $37{ }^{\circ} \mathrm{C}$ durante 6-8 horas. Posteriormente, con un asa redonda esterilizada se depositaron tres asadas de la superficie del cultivo de APA en una placa de agar selectivo TCBS (agar tiosulfato-citrato-sal de Bilis-sacarosa). La temperatura de incubación fue $37^{\circ} \mathrm{C}$, por 18-24 horas.

\section{Caracterización bioquímica}

Se seleccionaron del agar TCBS colonias sacarosa positivas (colonias amarillas, planas, de aproximadamente $2 \mathrm{~mm}$, generalmente pegajosas) o sacarosas negativas (colonias verdes, de aproximadamente $2 \mathrm{~mm}$, generalmente pegajosas). Se inocularon tubos de caldo arginina (base descarboxilasa de Moeller y L-arginina) y caldo peptonado (peptona de caseína $2 \%, \mathrm{NaCl} 0.5 \%$ ), medio de movilidad indol ornitina, agar de hierro y triple azúcar, y agar de hierro y lisina con la misma colonia de bacterias crecidas en la observación anterior. Debido al requerimiento de $\mathrm{NaCl}$ por parte de $V$. cholerae, se sembraron caldos nutritivos con 0, 1, 3, 6, 8 y 10\% de $\mathrm{NaCl}$. La identificación bioquímica de $V$. cholerae se realizó siguiendo los lineamientos del cuadro 2 del anexo 2 de los Lineamientos para la vigilancia epidemiológica de la enfermedad diarreica aguda bacteriana por laboratorio ${ }^{7}$ del Instituto de Diagnóstico y Referencia Epidemiológicos (InDRE) Dr. Manuel Martínez Báez, de la Secretaría de Salud de México.

\section{Serotipificación}

Una vez identificada bioquímicamente la presencia de $V$. cholerae en las muestras fecales, se procedió a realizar la serotipificación a partir de una placa de base agar sangre (BAB). Para ello, en un portaobjetos limpio y desengrasado se depositaron cuatro gotas separadas de solución salina formalinizada en el extremo superior del portaobjetos, y en el extremo inferior se colocaron una gota de solución salina (testigo negativo), una gota de suero polivalente $V$. cholerae
O1, una gota de suero monovalente $V$. cholerae 01 Ogawa y una gota de suero monovalente $V$. cholerae 01 Inaba. Se tomó con un asa estéril crecimiento bacteriano de la placa de BAB y se mezcló con cada una de las gotas descritas anteriormente en busca de aglutinación.

\section{Producción de toxina colérica}

Para determinar la capacidad de producción de la toxina colérica se utilizó la técnica de ELISA descrita anteriormente ${ }^{5}$, utilizando sobrenadantes de cultivos de cepas.

\section{Biotipos}

Después de identificar el grupo y el serotipo, se procede a la caracterización del biotipo (clásico o El Tor). Esto se realiza con cepas crecidas en BAB y se analiza la inhibición de crecimiento por la presencia de polimixina $\mathrm{B}$, la presencia de hemólisis y la aglutinación de eritrocitos de pollo o carnero; todos ellos fenotipos diferenciales entre los dos biotipos.

\section{Perfiles de sensibilidad a antibióticos}

La sensibilidad a antibióticos de todas las cepas de $V$. cholerae se determinó utilizando el método de difusión en disco en agar Mueller-Hinton. Los antibióticos utilizados (Oxoid, UK) fueron ampicilina, amoxicilina, ciprofloxacino, levofloxacino, tetraciclina, nitrofurantoína y trimetoprima-sulfametaxol. Los datos fueron comparados con los publicados por el Clinical and Laboratory Standard Institute (CLSI, versión 2011).

\section{Reacción en cadena de la polimerasa de los genes que codifican para las toxinas CtxA, CtxB, Zot y Ace}

Una vez identificada la presencia de $V$. cholerae en las muestras fecales e identificados el serotipo y el biotipo, se procedió a determinar la presencia de los genes que codifican para las toxinas previamente reportadas en las cepas aisladas. Para ello se mezcló una colonia caracterizada como V. cholerae en 200 $\mu \mathrm{l}$ de agua destilada para obtener el DNA molde; la suspensión se hirvió durante 15 minutos e inmediatamente se transfirió a un contenedor con hielo. La mezcla de cada reacción en cadena de la polimerasa (PCR) contenía $3 \mu \mathrm{l}$ de la suspensión, $9.35 \mu \mathrm{l}$ de $\mathrm{H}_{2} \mathrm{O}$, 
$2.5 \mu \mathrm{l}$ de buffer Taq 10X, $4.0 \mu \mathrm{l}$ de $\mathrm{MgCl}_{2} 25 \mathrm{mM}, 4.0$ $\mu \mathrm{l}$ de dNTP $1 \mu \mathrm{M}, 1.0 \mu \mathrm{l}$ de los iniciadores 1 (ctx 2, ctx 7 , ace 1 , zot 1, 1-39Vc) y 2 (ctx 3, ctx 9, ace 2, zot 2, 2-39Vc), y $0.15 \mu \mathrm{l}$ de Taq $5 \mathrm{U} / \mu \mathrm{l}$ Roche. El programa utilizado consistió en un ciclo a $94{ }^{\circ} \mathrm{C} 1 \mathrm{~min} ; 35$ ciclos a $94{ }^{\circ} \mathrm{C} 30 \mathrm{~s}, 55^{\circ} \mathrm{C} 30 \mathrm{~s}, 72{ }^{\circ} \mathrm{C} 1 \mathrm{~min}$, y un ciclo a $72{ }^{\circ} \mathrm{C} 2 \mathrm{~min}$. La secuencia de los iniciadores fue la siguiente:

\begin{tabular}{|c|c|}
\hline mbre & Secuencia \\
\hline $\operatorname{ct} x 2$ & 5'-CGGGCAGATTCTAGACCTCCTG-3' \\
\hline $\operatorname{ctx3}$ & 5'-CGATGATCTTGGAGCATTCCCAC-3' \\
\hline$c t x 7$ & $\begin{array}{l}\text { 5'-GGTTGCTTCTCATCATCGAAC } \\
\text { CAC-3' }\end{array}$ \\
\hline $\operatorname{ct} x 9$ & 5'-GATACACATAATAGAATTAAGGAT-3' \\
\hline ace1 & $\begin{array}{l}5^{\prime}-T A A G G A T G T G C T T A T G A T G G A C A \\
\text { CCC-3' }\end{array}$ \\
\hline$c e 2$ & 5'-CGTGATGAATAAAGATACTCATAG-3' \\
\hline zot1 & $\begin{array}{l}5^{\prime}-T G G C T T C G T C T G C T G C C G G C G \\
\text { ATT-3' }\end{array}$ \\
\hline $1-39 V c$ & 5'-GCGTTATAGGTATCATCAAGAGA-3' \\
\hline$-39 V c$ & 5'-GTCATTATTAAAACTGCTCCATT-3' \\
\hline
\end{tabular}

Los productos de DNA obtenidos se sometieron a un procedimiento de electroforesis en gel de agarosa al $2 \%$ en amortiguador Tris-EDTA-ácido acético a 120 $\checkmark$ por 30 minutos. El patrón de bandeo de fragmentos de DNA revelado por tinción del gel con bromuro de etidio expuesto a luz ultravioleta fue analizado para comparación con los tamaños de los fragmentos correspondientes a los genes de las subunidades $A$ y $B$ de la toxina colérica y a los genes de las toxinas accesorias Ace y Zot.

\section{Electroforesis por campos pulsados}

La electroforesis por campos pulsados (PFGE) se realizó basándose en el protocolo PulseNet (CDC, Atlanta, GA, EE.UU.) para V. cholerae y los procedimientos descritos anteriormente. La digestión de DNA se llevó a cabo con las enzimas Notl $40 \mathrm{U}$ a $37^{\circ} \mathrm{C}$ y Sfil $50 \mathrm{U}$ a $50^{\circ} \mathrm{C}$ durante 4 horas. Se utilizó el CHEFMapper (Bio-Rad) para electroforesis y el tiempo de pulso varió de 1 a 20 segundos durante 13 horas, y de 20 a 25 segundos por 6 horas. El gel se tiñó usando Gelred (Biofilm) y se visualizó usando el sistema de imágenes de gel (Bio-Rad, Gel DocXR). Los patrones de PFGE se analizaron con BioNumerics versión 5.10 y se realizó un dendograma utilizando el algoritmo UPGMA ${ }^{9}$.

\section{Secuenciación del genoma de Vibrio cholerae}

Los genomas de $V$. cholerae aislados en los Estados de Hidalgo, Estado de México, Veracruz y Ciudad de México (cepas identificadas como InDRE3683, InDRE4262, InDRE4354 e InDRE3140, respectivamente) fueron secuenciados utilizando la plataforma 454 FLX-Titanium platform (Roche, Brandford, CT) ${ }^{10}$. Se generaron bibliotecas a partir de DNA genómico y se obtuvieron lecturas variables en cada genoma. Los primeros borradores de los genomas se ensamblaron utilizando el software Newbler (versión 2.9), con las secuencias de V. cholerae 2010EL-1786 como cepa de referencia (GenBank CP003069.1 y CP003070.1).

\section{Resultados}

\section{Identificación de casos iniciales}

Los días 2 y 6 de septiembre de 2013, el Sistema Nacional de Vigilancia Epidemiológica identificó dos casos de cólera en Ciudad de México. Los cultivos de las muestras de hisopo rectal de ambos pacientes fueron confirmados bioquímicamente como $V$. cholerae serogrupo 01, serotipo Ogawa, biotipo El Tor, toxigénico. Teniendo como antecedente la séptima pandemia que afectó a México por 11 años, se realizaron estudios de epidemiologia molecular para proveer datos sólidos que permitieran caracterizar las cepas aisladas de estos dos casos. Inicialmente se amplificaron por PCR los genes de virulencia (ctxA, ctxB, zot y ace). Al comparar los productos de PCR se demostró que ambos aislamientos compartían los mismos fragmentos entre sí, lo que sugirió fuertemente que eran derivadas de la misma cepa. Muy importante fue el hecho de que, claramente, estas cepas aisladas eran diferentes de las cepas circulantes en ese momento en México. El análisis detallado de los patrones de bandas confirmó que ambas cepas eran prácticamente idénticas a la cepa causante de los brotes actuales en Haití, República Dominicana y Cuba ${ }^{11}$.

Entre el 12 y el 13 de septiembre, el Laboratorio Estatal de Salud Pública del Estado de Hidalgo identificó cuatro casos de cólera en residentes de la 
región de la Huasteca, localizada $121 \mathrm{~km}$ al este de Ciudad de México, habitada fundamentalmente por indígenas otomíes y náhuatls. Entre el 19 de septiembre y el 15 de diciembre de 2013 se confirmaron 175 casos de cólera en La Huasteca (159 en Hidalgo, 14 en Veracruz y 2 en San Luis Potosí) (Tabla 1 y Fig. 1).

\section{Definición de casos e identificación bioquímica}

Los casos de La Huasteca se clasificaron de acuerdo con el Manual de procedimientos estandarizados para la vigilancia epidemiológica de cólera (DGE, Secretaría de Salud de México) y se definieron según la clasificación de la Organización Mundial de la Salud (OMS). Todos fueron confirmados por laboratorio como V. cholerae serogrupo 01 , serotipo Ogawa, biotipo El Tor, toxigénico, idénticos a los aislamientos de Ciudad de México e indistinguibles de la cepa circulante en el Caribe. Todos los casos se reportaron a la OMS a través del Punto Focal para el Reglamento Sanitario Internacional en México. Es de destacar que el $75 \%$ de los pacientes fueron

Tabla 1. Casos confirmados por municipio

\begin{tabular}{|c|c|c|}
\hline Municipio & Estado & Casos \\
\hline Ajacuba & Hidalgo & 1 \\
\hline Huejutla & Hidalgo & 119 \\
\hline Metztitlán & Hidalgo & 2 \\
\hline Mineral del Chico & Hidalgo & 1 \\
\hline Molango de Escamilla & Hidalgo & 2 \\
\hline Pachuca de Soto & Hidalgo & 3 \\
\hline San A. Metzquititlán & Hidalgo & 1 \\
\hline San Bartolo Tutotepec & Hidalgo & 4 \\
\hline Tinaguistengo & Hidalgo & 5 \\
\hline Tlanchinol & Hidalgo & 5 \\
\hline Tula de Allende & Hidalgo & 4 \\
\hline San Agustín Tlaxiaca & Hidalgo & 1 \\
\hline Xochiatipán & Hidalgo & 6 \\
\hline Xochicoatlán & Hidalgo & 1 \\
\hline Yahualica & Hidalgo & 3 \\
\hline Zacualtipán & Hidalgo & 1 \\
\hline Benito Juárez & Veracruz & 3 \\
\hline Platón Sánchez & Veracruz & 2 \\
\hline Te mpoal & Veracruz & 2 \\
\hline Texcatepec & Veracruz & 4 \\
\hline Tihuatlán & Veracruz & 3 \\
\hline Ciudad Valles & San Luis Potosí & 2 \\
\hline Total & & 175 \\
\hline
\end{tabular}

residentes de áreas vecinas a El Tecoluco y El Chinguiñoso, afluentes del Río Pánuco. Los aislamientos de $V$. cholerae recuperados de ambos afluentes fueron idénticos a la cepa del brote. Las muestras obtenidas del drenaje municipal, puestos de pescado, restaurantes y fuentes de agua potable fueron evaluadas para identificar potenciales sitios de brotes. Por la ubicación geográfica de los puntos donde se obtuvieron casos es muy sugerente que el vehículo de transmisión fue el agua.

Por ello, la necesidad de tener una caracterización bioquímica y molecular de las cepas del brote fue fundamental para establecer mecanismos de prevención y control de la epidemia. Cabe destacar que el $49 \%$ de los casos fueron en mujeres con un promedio de 32 años (rango 3-83 años), y el promedio de duración de la hospitalización fue de 36 horas. Todos los pacientes presentaron diarrea acuosa aguda, y de ellos, el $26 \%$ produjeron heces de «agua de arroz»; el $43 \%$ tuvo leve, el $18 \%$ moderada y el $3 \%$ grave deshidratación. Un paciente falleció. El espectro de la enfermedad en este brote difiere del observado en los brotes notificados en el Caribe ${ }^{12}$. Justo después de esta identificación, la epidemia se extendió a los Estados de México, Hidalgo, San Luis Potosí y Veracruz. Las pruebas bioquímicas y de epidemiología molecular de cultivos de muestras de pacientes confirmaron la presencia de V. cholerae O1 El Tor Ogawa. El perfil de sensibilidad a los antibióticos fue similar al observado previamente en las cepas de $V$. cholerae del Caribe (Tabla 2).

\section{Epidemiología molecular}

Se decidió realizar estudios de PFGE para determinar la identidad de la cepa causante del brote. El análisis inicial fue determinar los patrones de PFGE de las cepas de $V$. cholerae circulantes en México (previas a este estudio) con cepas reportadas en otros brotes, obteniendo que el sistema BioNumerics arroja dos grupos donde se observan, por un lado, las cepas toxigénicas de Haití y Sudáfrica en una rama, mientras que todas las mexicanas se desprenden de otra (Fig. 2).

Es importante señalar que los patrones probados de las cepas 2, 3, 01 y 540415 fueron los reportados en el brote de Haití de 2010 que causó más de 700,000 casos de cólera.

Entonces se procedió a estudiar las cepas que se aislaron por primera vez en la Ciudad de México, y como se observa en la figura 3, mostraron un $97 \%$ de 


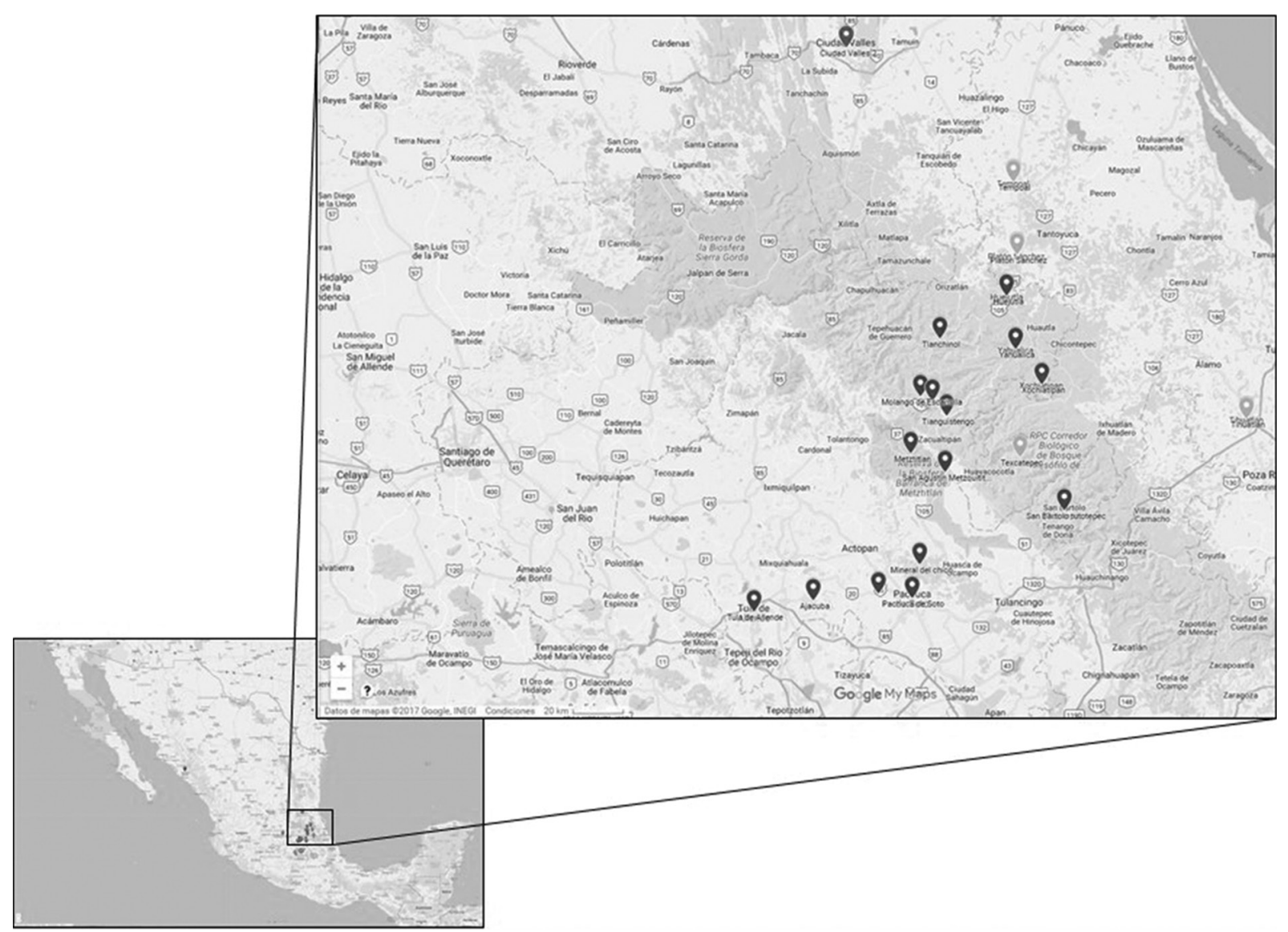

Figura 1. Mapa de la región de La Huasteca, México. Se muestran los lugares donde se detectaron casos de cólera en la zona.

Tabla 2. Patrón de sensibilidad a antibióticos

\begin{tabular}{llll}
\hline Antibiótico & $\begin{array}{l}\text { Cepa del brote en el } \\
\text { Caribe }\end{array}$ & $\begin{array}{l}\text { Cepas aisladas en Ciudad de } \\
\text { México }\end{array}$ & $\begin{array}{l}\text { Cepas aisladas en } \\
\text { Hidalgo }\end{array}$ \\
\hline Trimetoprima-sulfametaxol & $\mathrm{R}$ & $\mathrm{R}$ & $\mathrm{R}$ \\
Furazolidona & $\mathrm{R}$ & $\mathrm{R}$ & $\mathrm{R}$ \\
Doxiciclina & $\mathrm{S}$ & $\mathrm{S}$ & $\mathrm{S}$ \\
Ciprofloxacino & $\mathrm{S}$ Disminuida & $\mathrm{S}$ Disminuida & $\mathrm{S}$ Disminuida \\
Ampicilina & $\mathrm{I}$ & $\mathrm{I}$ & $\mathrm{I}$ \\
Cloramfenicol & $\mathrm{I}$ & $\mathrm{S}$ & $\mathrm{S}$ \\
\hline S: sensible: R: resistente: I: intermedia & & &
\end{tabular}

similitud con una cepa aislada en Cuba durante el brote de 2010 en el Caribe. Por lo tanto, quedó claro que la cepa que causó el brote de 2013 en México fue diferente a las previamente aisladas, pero similar a las que causaron el brote en el Caribe. Para apoyar aún más esta observación se realizó PFGE de 19 diferentes cepas aisladas en humanos durante este brote y también de dos muestras aisladas del medio ambiente, todas de la región de La Huasteca (Fig. 1). Se observó que todas las cepas eran $100 \%$ similares entre ellas y también con las cepas aisladas en Ciudad de México; por lo tanto, muy similares a la cepa aislada en Cuba durante el brote de 2010 en el Caribe (Fig. 3).

Al comparar las cepas de $V$. cholerae que fueron aisladas a lo largo de este estudio, tanto en humanos como en muestras ambientales, se observó que todas tenían un patrón de PFGE 100\% similar entre ellas y también con la cepa aislada de Cuba durante la epidemia del Caribe en 2010 (Fig. 4). 


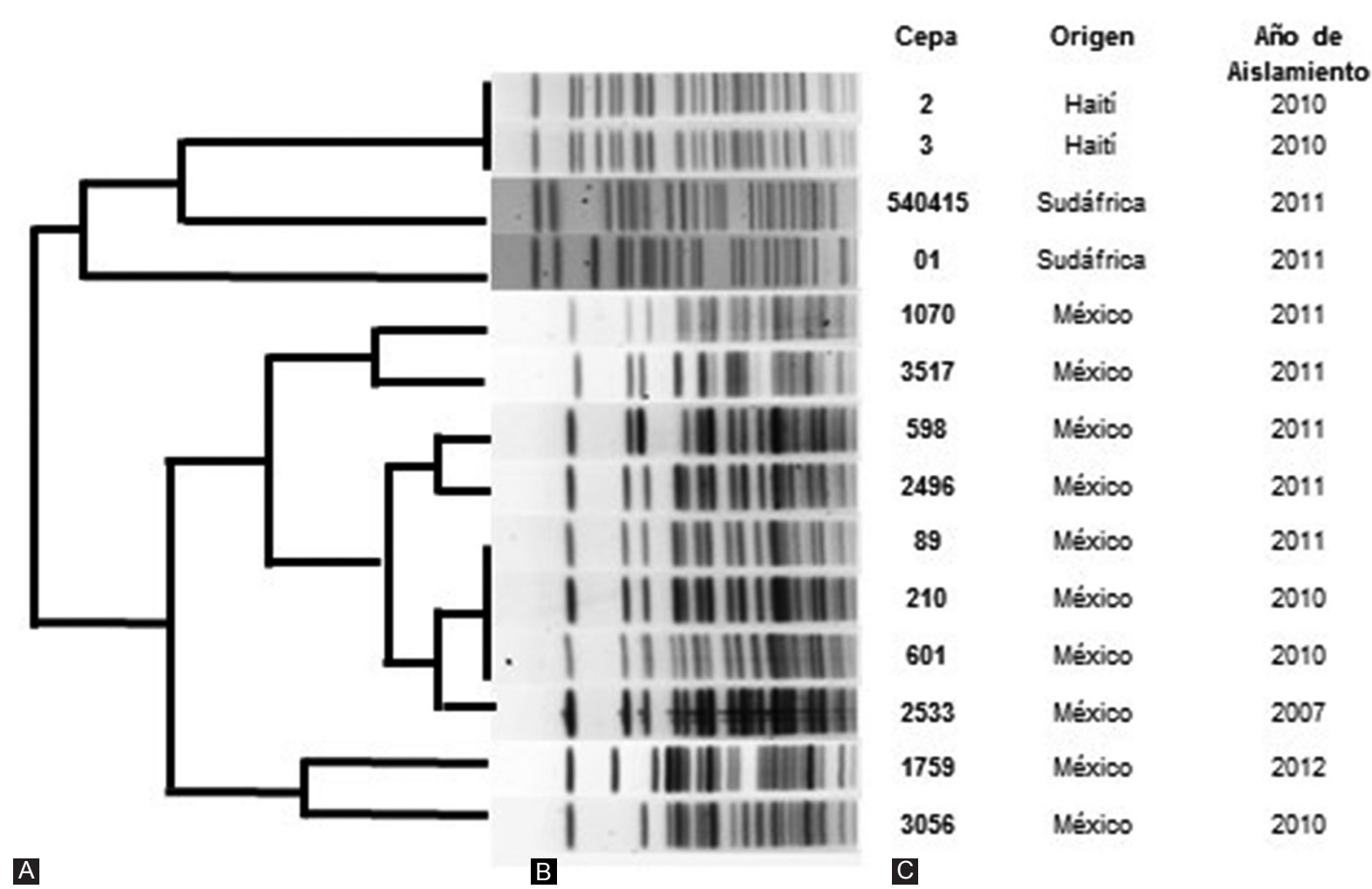

Figura 2. PFGE de diferentes cepas encontradas en Haití, Sudáfrica y México. A: dendograma de las similitudes entre los diferentes patrones utilizando el sistema Bionumerics. B: patrones de bandas de las cepas indicadas. C: nombre de la cepa, origen y año de aislamiento (modificada de Díaz-Quiñonez JA, et al. ${ }^{13}$ ).

\section{Secuenciación de genomas completos de Vibrio cholerae}

Se obtuvo la secuencia de los genomas completos de cuatro cepas identificadas como InDRE3683, InDRE4262, InDRE4354 e InDRE3140, correspondientes a cepas de $V$. cholerae aisladas en los Estados de Hidalgo, Estado de México, Veracruz y Ciudad de México, respectivamente, mediante secuenciación de siguiente generación. Las lecturas obtenidas para cada una de las cepas fueron utilizadas para mapear la secuencia completa utilizando como referencia la secuencia de la cepa V. cholerae 2010 EL-1786. Los contigs obtenidos mediante el mapeo para cada cepa se analizaron con la herramienta BLASTn del NCBI para la búsqueda de identidades, encontrándose que la secuencia nucleotídica de los genomas completos de las cuatro cepas se agrupa mayoritariamente con la cepa V. cholerae 2010 EL-1786, previamente reportada en el brote de Haití en 2010.

Los contigs obtenidos fueron anotados usando el software NCBI Prokaryotic Genome Annotation Pipeline con el mejor set posicionado de proteínas de referencia, GeneMarkS+ method, versión 2.6 (revisión
440435). El número de contigs obtenidos para cada genoma, longitud y cobertura se encuentra descrito en la Tabla 3.

Una vez anotada la secuencia de cada cepa se realizó la búsqueda por mapeo específico de algunos elementos de importancia biológica para la bacteria, como las islas de patogenicidad VPI-1 y VPI-2, VSP-1 y VSP2 , el elemento integrativo y conjugativo SXT, además de la toxina colérica y el profago RS1, utilizando como referencia para el mapeo la secuencia de la cepa $V$. cholerae 2010 EL-1786, delimitando la posición en el genoma de cada uno de los elementos mencionados. Como resultado de este análisis molecular se confirmó la presencia de los mismos elementos, tanto en la cepa de referencia como en las cuatro cepas estudiadas. La identidad obtenida en el BLASTn y la presencia en las cuatro cepas de las islas de patogenicidad VPI-1 y VPI-2, VSP-1 y VSP-2, el elemento integrativo y conjugativo SXT, además de la toxina colérica y el profago RS1, nos demuestran que la estructura genómica de estos cuatro aislamientos fue similar entre ellas y con la de la cepa V. cholerae 2010 EL-1786. Esto concuerda con el resultado inicial obtenido a partir de los estudios de PFGE. 


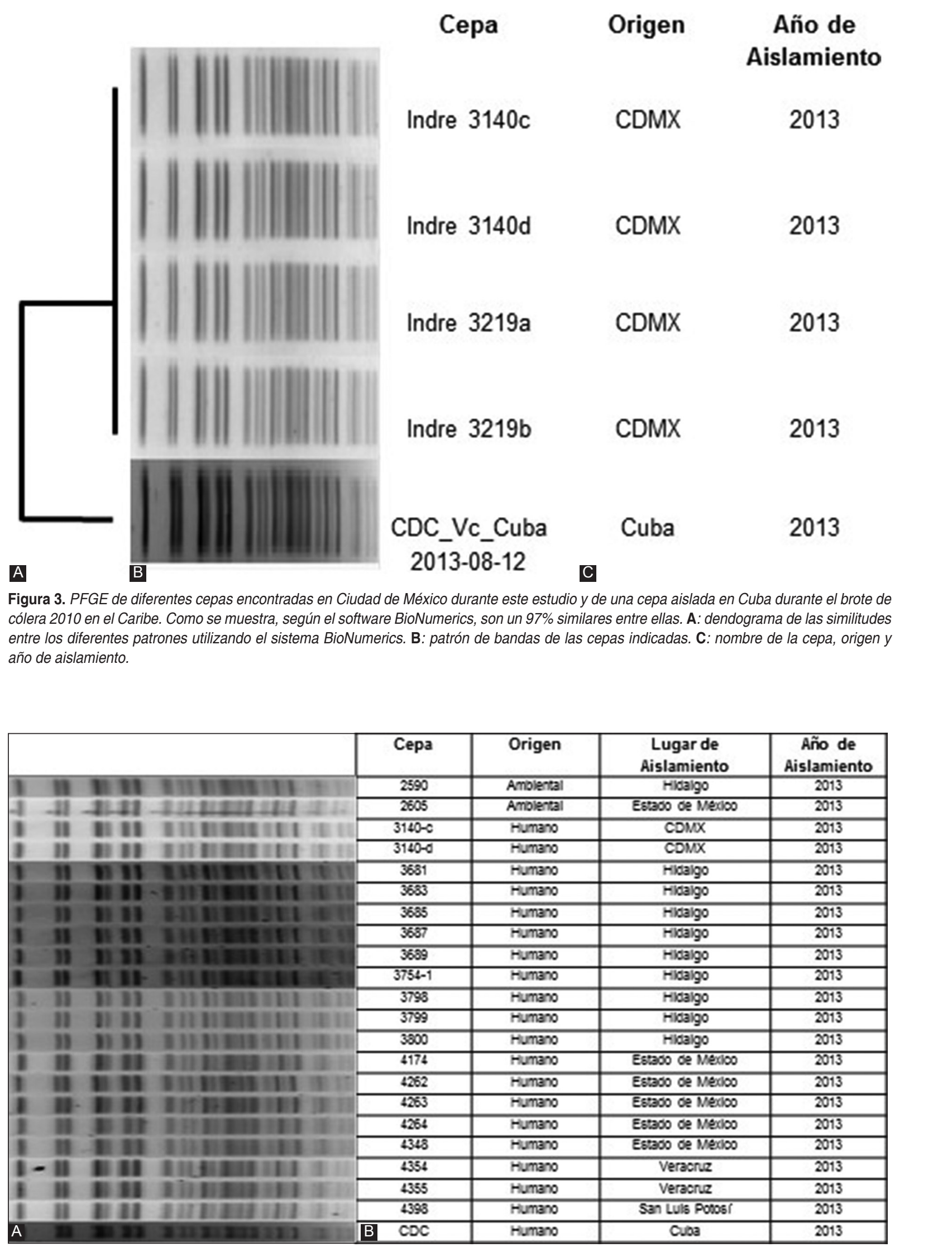

Figura 4. PFGE de diferentes cepas aisladas tanto en humanos como en muestras ambientales en diferentes entidades federativas donde ocurrió el brote de cólera en 2013. El patrón de bandas es 100\% similar entre ellas y con la cepa aislada en Cuba en 2010. 
Tabla 3. Genomas secuenciados, longitud y cobertura. Se indican la cepa, el lugar donde fue colectada, el número de contigs analizados, el número de lecturas (Reads), la cobertura (número de veces que el genoma total fue analizado), la longitud (en pares de bases) y el número de acceso en Genbank

\begin{tabular}{llcccccc}
\hline Cepa & Lugar & Contigs & Reads & Cobertura & $\begin{array}{c}\text { Cobertura } \\
\mathbf{2}\end{array}$ & Longitud & Genbank ACC\# \\
\hline 3140 & Ciudad de México & 92 & 205226 & $18 X$ & $16 X$ & 4017985 & JPHJ010000000 \\
3683 & Hidalgo & 1091 & 150552 & $13.24 X$ & $15.13 X$ & 3871676 & JZTZ010000000 \\
4262 & Estado De México & 52 & 223459 & $19.88 X$ & $12.74 X$ & 4019893 & JZUB00000000 \\
4354 & Veracruz & 47 & 264438 & $21.01 X$ & $20.89 X$ & 40019937 & JZUA00000000 \\
\hline
\end{tabular}

\section{Análisis filogenómico}

Para entender mejor la ascendencia genética de las cepas del brote de la región Huasteca mexicana, se construyó un árbol filogenómico con los cuatro genomas completos aquí descritos y todos los contigs disponibles de 22 cepas de $V$. cholerae. El árbol filogenómico resultante mostró una agrupación de los cuatro aislamientos mexicanos en el filogrupo 1 pertenecientes al séptimo clado pandémico, en el que se incluyó el aislado mexicano anterior de 1991 (Fig. 5). Las filogenias para secuencias de genoma completo mostraron que las cuatro secuencias aquí descritas están genéticamente relacionadas con las cepas del brote de Haití en 2010. Estos datos confirman la relación genética también inferida por la serotipificación, la biotipificación y la PFGE, y apoyan la inclusión de las cepas causantes del brote en La Huasteca en el filogrupo 1 de la séptima pandemia ${ }^{14}$.

\section{Discusión}

La última epidemia de cólera en México se registró de 1991 a 2001, y se reportaron un total de 45,062 casos confirmados con una tasa de mortalidad del $1.1 \%$. Se requirieron 11 años para controlarla. Casos posteriores de infección por $V$. cholerae serogrupo 01 han ocurrido esporádicamente en México. La vigilancia epidemiológica convencional permitió la identificación de un caso en 2010, uno en 2011 y dos en 2012 en Sinaloa. Los dos primeros fueron por $V$. cholerae serotipo Inaba y los otros dos por $V$. cholerae serotipo Ogawa. A través de la epidemiologia molecular se identificó rápidamente que dichas cepas eran las mismas del brote de 1991 a $2001^{5,15}$. La cepa InDRE3140 se identificó como la causante del brote de cólera de la región de La Huasteca en 2013; las pruebas bioquímicas, serológicas y microbiológicas identificaron esta cepa como V. cholerae 01 serotipo Ogawa biotipo El
Tor. Sin embargo, la pronta utilización de herramientas de epidemiologia molecular, tanto la secuenciación de los genes de virulencia como el patrón de PFGE, así como la secuenciación y el análisis del genoma completo de la bacteria, confirmó sin lugar a dudas que se trataba de la misma cepa que causó brotes en Haití, la República Dominicana y Cuba. Este conocimiento permitió diseñar estrategias de vigilancia epidemiológica y acciones de prevención y control que tuvieron como resultado que el brote de La Huasteca fuera controlado en las primeras 13 semanas a partir de la identificación del caso índice. Se estableció un laboratorio móvil en Huejutla para el rápido diagnóstico y tratamiento de pacientes con el fin de interrumpir la transmisión. Durante 2014 solo se confirmaron 14 casos de cólera como reminiscencia del brote de 2013 en dos entidades federativas: Hidalgo (13 casos) y Querétaro (un caso). Las acciones de prevención y control han contribuido a que, al día de hoy y desde el inicio de 2015, no se hayan reportado nuevos casos de cólera en México.

El cólera ha tenido un efecto muy grande en la historia de la humanidad ${ }^{1,2,17}$. A pesar de ello, las estrategias de control han demostrado ser poco efectivas en zonas donde el cólera es endémico, ya que invariablemente va ligado al pobre desarrollo económico de los países que lo padecen. Al momento estamos inciertos sobre si surgirá un nuevo serogrupo, como sucedió con el serogrupo 0139. ¿Realmente estamos preparados para detectarlo a tiempo? La epidemiología molecular representa una herramienta valiosa en estos casos, considerando que los fenómenos del calentamiento global y el cambio climático están alterando las temperaturas de los cuerpos de agua, sitios por excelencia de crecimiento de la bacteria. Una combinación de vigilancia epidemiológica tradicional, en conjunto con la epidemiologia molecular y el apoyo de laboratorios móviles in situ, resultó ser una estrategia muy efectiva para tratar brotes como el que ocurrió en La Huasteca en 2013. 


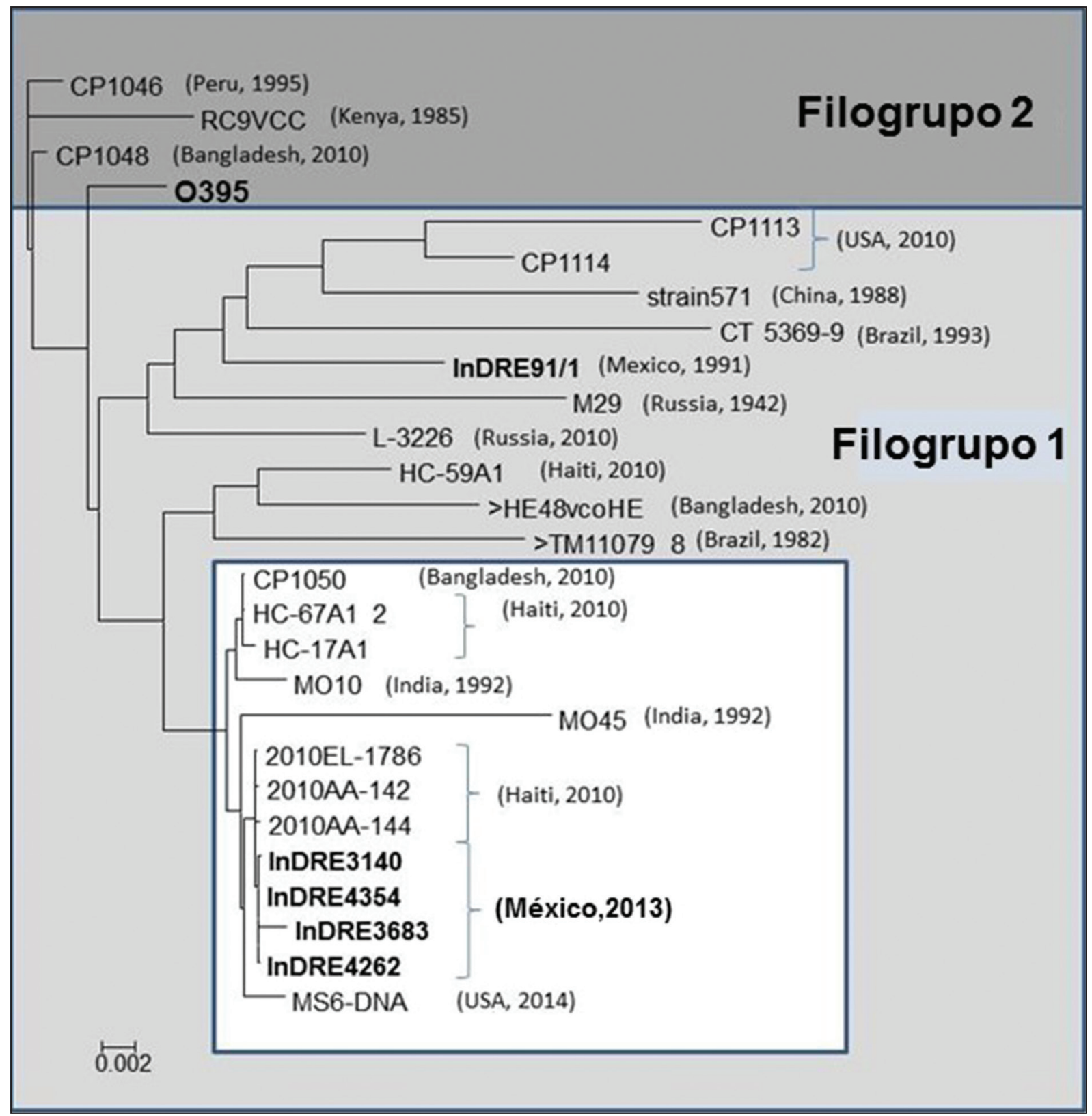

Figura 5. Análisis filogenómico de genomas completos de Vibrio cholerae utilizando la técnica de unión de vecinos (neighbour joining). Los genomas de las cepas de V. cholerae InDRE3683, InDRE4262, InDRE4354 e InDRE3140 se dispusieron en formato FASTA para ser comparadas con los 22 genomas disponibles de V. cholerae (modificada de Díaz-Quiñonez JA, et al. ${ }^{16}$ ).

\section{Conclusiones}

Este estudio, realizado durante la epidemia de cólera de 2013 en La Huasteca, ilustra la manera en que la investigación epidemiológica tradicional puede enriquecerse con herramientas moleculares como la PFGE, la PCR, la secuenciación genómica y los análisis filogenómicos. Profesionales de la salud debidamente entrenados, tecnología de vanguardia y procedimientos estándares son indispensables para ello. La última epidemia de cólera en México requirió 11 años para ser controlada. En contraste, utilizando las estrategias aquí descritas, el brote de La Huasteca fue contenido en solo 13 semanas. Los datos aquí presentados arrojan la evidencia bioquímica, serológica y molecular de que la cepa causante del brote de cólera en La Huasteca fue la misma que se detectó previamente en Ciudad de México y es indistinguible de la cepa que ha causado una epidemia devastadora en Haití desde el año 2010. El despliegue de un laboratorio móvil de salud pública en la zona de La Huasteca resultó una estrategia clave al permitir diagnosticar y tratar 
pacientes rápidamente para interrumpir la transmisión. La vigilancia microbiológica permanente de casos de infección y contaminación de cuerpos de agua por $V$. cholerae, a través de la Red Nacional de Laboratorios de Salud Pública, continúa activa para detectar de manera oportuna las cepas con potencial patogénico en México. Finalmente, la epidemiología molecular representa una herramienta muy poderosa para vigilar enfermedades de importancia en salud pública.

\section{Agradecimientos}

El autor agradece especialmente al Dr. Alfonso Méndez-Tenorio por compartir el software de hibridación virtual. También se valora la aportación de todo el staff de los Departamentos de Biología Molecular y de Virología del InDRE.

\section{Bibliografía}

1. Sack DA, Sack RB, Nair GB, et al. Cholera. Lancet. 2004;363:223-33.

2. Harris JB, LaRocque RC, Qadri F, et al. Cholera. Lancet. 2012; 379:2466-76.

3. Page AL, Ciglenecki I, Jasmin ER, et al. Geographic distribution and mortality risk factors during the Cholera outbreak in a rural region of Haiti 2010-2011. Plos Negl Trop Dis. 2015;26:e0003605.

4. Waldor MK, Tschape H, Mekalanos JJ. A new type of conjugative transposon encodes resistance to sulfamethoxazole, trimethoprim, and streptomycin in Vibrio cholerae 0139. J Bacteriol. 1996; 178:4157-65.
5. Alam M, Rashed SM, Mannan SB, et al. Ocurrence in Mexico, 19982008, of Vibrio cholerae $\mathrm{CTX}^{+} \mathrm{El}$ Tor carrying an additional truncated CTX prophage. Proc Natl Acad Sci. 2014;27:9917-22.

6. Alam M, Islam MT, Rashed SM, et al. Vibrio cholerae classical biotype strains reveal distinct signatures in Mexico. J Clin Microbiol. 2012; 50:2212-16

7. Instituto de Diagnóstico y referencia Epidemiológicos Dr. Manuel Martínez Báez. Dirección General de Epidemiología. Secretaría de Salud. México; 2015. Lineamientos para la vigilancia epidemiológica de la enfermedad diarreica aguda bacteriana por laboratorio. Disponible en: https://www.gob.mx/cms/uploads/attachment/file/65726/Lineamientos_ para la vigilancia epidemiologica de enfermedad diarreica aguda.pdf

8. Clinical and Laboratory Standards Institute. Performance standards for antimicrobial susceptibility testing, twenty third informational supplement. M100-S23. Wayne, PA,USA: CLSI; 2013,

9. Cameron DN, Khambaty FM, Wachsmuth IK, et al. Molecular characterization of Vibrio cholerae $\mathrm{O} 1$ strains by pulsed-field gel electrophoresis. J Clin Microbiol. 199;32:1685-90.

10. Reyes MA, Méndez A, Maldonado R, et al. Fingerprinting of prokaryotic 16S rRNA genes using oligodeoxyribonucleotide microarrays and virtual hybridization. Nucl Acid Res. 2003;31:779-89.

11. Talkington $D$, Bopp $C$, Tarr $C$, et al. Characterization of toxigenic Vibrio cholerae from Haiti, 2010-2011. Emerg Infect Dis. 2011;17:2122-9.

12. Jackson BR, Talkington DF, Pruckler JM, et al. Seroepidemiologic survey of epidemic cholera in Haiti to assess spectrum of illness and risk factors for severe disease. Am J Trop Med and Hyg. 2013;89:654-64.

13. Díaz-Quiñonez JA, Hernández-Monroy I, Montes-Colima NA, et al. Biochemical and full genome sequence analyses of clinical Vibrio cholerae isolates in Mexico reveals the presence of novel $V$. cholerae strains. Microbes Infect. 2016;18:322-8

14. Reimer AR, Van Domselaar G, Stroika S, et al. Comparative genomics of Vibrio cholerae from Haiti, Asia, and Africa. Infect Dis. 2011;11:2113-21.

15. Hernández-Vázquez $\mathrm{E}$. Caracterización epidemiológica del cólera en México a partir de su re-introducción, 2013-2014. Universidad Nacional Autónoma de México. Tesis de Especialidad en Epidemiología. Facultad de Medicina; 2016.

16. Díaz-Quiñonez JA, Hernández-Monroy I, López-Martínez I, et al. Genome sequence of Vibrio cholerae Strain O1 Ogawa El Tor, isolated in Mexico 2013. Genome Annouc. 2014;2:e01123-14.

17. Díaz-Quiñonez JA, Hernández-Monroy I, Montes-Colima N, et al. Outbreak of Vibrio cholerae serogroup 01, serotype Ogawa, biotype El Tor strain - La Huasteca Region, Mexico, 2013. MMWR Morb Mortal Wkly Rep. 2014;63:552-3. 